\title{
Molecular Series-Tunneling Junctions
}

\section{Citation}

Liao, Kung-Ching, Liang-Yan Hsu, Carleen M. Bowers, Herschel Rabitz, and George M. Whitesides. 2015. "Molecular Series-Tunneling Junctions." Journal of the American Chemical Society 137 (18) (May 13): 5948-5954. doi:10.1021/jacs.5b00448.

\section{Published Version}

doi:10.1021/jacs.5b00448

\section{Permanent link}

http://nrs.harvard.edu/urn-3:HUL.InstRepos:25042503

\section{Terms of Use}

This article was downloaded from Harvard University's DASH repository, and is made available under the terms and conditions applicable to Open Access Policy Articles, as set forth at http:// nrs.harvard.edu/urn-3:HUL.InstRepos:dash.current.terms-of-use\#OAP

\section{Share Your Story}

The Harvard community has made this article openly available.

Please share how this access benefits you. Submit a story.

Accessibility 


\section{Molecular Series-Tunneling Junctions}

Kung-Ching Liao, ${ }^{\dagger}$ Liang-Yan Hsu, ${ }^{\#, *}$ Carleen M. Bowers, ${ }^{\#, \dagger}$ Herschel Rabitz, ${ }^{*, \hbar}$ and George M. Whitesides*,,,,,$\|$

'Department of Chemistry and Chemical Biology, Harvard University, 12 Oxford Street, Cambridge, Massachusetts 02138 United States,

${ }^{\ddagger}$ Department of Chemistry, Princeton University, Princeton, New Jersey 08544, United States,

${ }^{\S}$ Wyss Institute for Biologically Inspired Engineering, Harvard University, 60 Oxford Street, Cambridge, Massachusetts 02138 United States, and "Kavli Institute for Bionano Science \& Technology, Harvard University, 29 Oxford Street, Massachusetts 02138 United States

\footnotetext{
${ }^{\#}$ Equal contributions

*Corresponding author, email:

hrabitz@princeton.edu (H.R.), gwhitesides@gmwgroup.harvard.edu (G.M.W.)
} 


\section{ABSTRACT}

Charge transport through junctions consisting of insulating molecular units is a quantum phenomenon that cannot be described adequately by classical circuit laws. This paper explores tunneling current densities in self-assembled monolayer (SAM)-based junctions with the structure $\mathrm{Ag}^{\mathrm{TS}} / \mathrm{O}_{2} \mathrm{C}-\mathrm{R}_{1}-\mathrm{R}_{2}-\mathrm{H} / / \mathrm{Ga}_{2} \mathrm{O}_{3} / \mathrm{EGaIn}$, where $\mathrm{Ag}^{\mathrm{TS}}$ is template-stripped silver, and EGaIn is the eutectic alloy of gallium and indium; $\mathrm{R}_{1}$ and $\mathrm{R}_{2}$ refer to two classes of insulating molecular units - $\left(\mathrm{CH}_{2}\right)_{\mathrm{n}}$ and $\left(\mathrm{C}_{6} \mathrm{H}_{4}\right)_{\mathrm{m}}$ - that are connected in series and have different tunneling decay constants in the Simmons equation. These junctions can be analyzed as a form of series tunneling junctions based on the observation that permuting the order of $R_{1}$ and $R_{2}$ in the junction does not alter the overall rate of charge transport. By using the $\mathrm{Ag} / \mathrm{O}_{2} \mathrm{C}$ interface, this system decouples the HOMO (which is localized on the carboxylate group) from strong interactions with the $\mathrm{R}_{1}$ and $\mathrm{R}_{2}$ units. The differences in rates of tunneling are thus determined by the electronic structure of the groups $\mathrm{R}_{1}$ and $\mathrm{R}_{2}$; these differences are not influenced by the order of $\mathrm{R}_{1}$ and $\mathrm{R}_{2}$ in the SAM. In an electrical potential model that rationalizes this observation, $\mathrm{R}_{1}$ and $\mathrm{R}_{2}$ contribute independently to the height of the barrier. This model explicitly assumes that contributions to rates of tunneling from the $\mathrm{Ag}^{\mathrm{TS}} / \mathrm{O}_{2} \mathrm{C}$ and $\mathrm{H} / / \mathrm{Ga}_{2} \mathrm{O}_{3}$ interfaces are constant across the series examined. The current density of these series tunneling junctions can be described by $J(V)=J_{0}(V) \exp \left(-\beta_{1} d_{1}-\beta_{2} d_{2}\right)$, where $J(V)$ is the current density $\left(\mathrm{A} / \mathrm{cm}^{2}\right)$ at applied voltage $V$, and $\beta_{i}$ and $d_{i}$ are the parameters describing the attenuation of the tunneling current through a rectangular tunneling barrier, with width $d$ and a height related to the attenuation factor $\beta$. 


\section{INTRODUCTION}

Charge transport by tunneling through metal-molecule-metal (MMM) junctions-junctions whose electronic features are modeled by a potential barrier ${ }^{1-9}$ and by molecular orbitals ${ }^{10-19}$ cannot be described adequately by classical diffusion, or by drift transport of charge. ${ }^{20-23}$ The classical circuit law states that the total resistance of two or more Ohmic resistors connected in series is the sum of the resistance of each resistor; that is, the sequence in which these resistors are assembled does not influence the overall current across the circuit. In quantum tunnelingwhere current between two conducting electrodes separated by a thin layer of insulating organic molecules decays exponentially with the length of molecules present in the junction-a classical circuit analysis based on Ohm's laws is not applicable. ${ }^{24,25}$ Joachim et al. ${ }^{26}$ used a theoretical approach based on elastic scattering quantum chemistry (Green's function method) to formulate rules describing tunneling transport through an insulating organic molecule comprising multiple molecular units in series. The rate of tunneling transport can also be modeled by a potential barrier generated by the insulating molecule; the shape of this barrier can be considered as a set of barriers contributed by the individual molecular units of which the molecule is made. An empirical examination of this model, however, has not yet been demonstrated, and an objective of this paper is to do so.

Here, we describe the rate of charge transport by tunneling through junctions of the form $\mathrm{Ag}^{\mathrm{TS}} / \mathrm{O}_{2} \mathrm{C}-\mathrm{R}_{1}-\mathrm{R}_{2}-\mathrm{H} / / \mathrm{Ga}_{2} \mathrm{O}_{3} / \mathrm{EGaIn}$, where $\mathrm{Ag}^{\mathrm{TS}}$ is template-stripped silver ${ }^{27}$ and EGaIn is the

eutectic alloy of gallium and indium; ${ }^{28}$ this junction has been characterized elsewhere in detail. ${ }^{28-36}$ $\mathrm{R}_{1}$ and $\mathrm{R}_{2}$ refer to two insulating molecular units, $\left(\mathrm{CH}_{2}\right)_{\mathrm{n}}$ and $\left(\mathrm{C}_{6} \mathrm{H}_{4}\right)_{\mathrm{m}}$, that are connected in series, and that have different barrier heights (Figure 1a).We consider the junction to be a "quantum series junction" 25 and evaluate a hypothesis as follows: If each segment $\left(\mathrm{R}_{1}\right.$ and $\left.\mathrm{R}_{2}\right)$ 
contributes independently to the shape of the tunneling barrier, changing the position of $R_{1}$ and $\mathrm{R}_{2}$ along the junction should not alter the overall rate of charge transport (Figure 1b). Using a junction of the form $\mathrm{Ag}^{\mathrm{TS}} / \mathrm{O}_{2} \mathrm{C}-\mathrm{R}_{1}-\mathrm{R}_{2}-\mathrm{H} / / \mathrm{Ga}_{2} \mathrm{O}_{3} / \mathrm{EGaIn}$, we varied the length and permuted the order of the aliphatic and aromatic units in the junction, and found that the rate of charge transport is sensitive to the electronic properties of the individual units, but not to the sequence in which they are assembled. We use a junction having the interface $\mathrm{Ag}^{\mathrm{TS}} / \mathrm{O}_{2} \mathrm{C}$, because the HOMO in this system is localized on the carboxylate group, and does not delocalize into either alkyl or aryl groups. (That is, using the carboxylate group to anchor the SAM to the bottom electrode, rather than a thiol, decouples the electrode and the interior of the SAM, so that the HOMO does not delocalize onto aromatic groups immediately proximate to the interface.) The contributions to rates of charge transport from the $\mathrm{Ag}^{\mathrm{TS}} / \mathrm{O}_{2} \mathrm{C}$ interface are thus constant across the series of molecules examined in this study-including both $\mathrm{O}_{2} \mathrm{C}-\left(\right.$ aryl R) and $\mathrm{O}_{2} \mathrm{C}-($ alkyl R) SAMs. When the groups $\left(\mathrm{R}_{1}\right.$ and $\left.\mathrm{R}_{2}\right)$ at the SAM-metal interfaces interact differently with the metal electrode (as with $\mathrm{Au} / \mathrm{S}-(\operatorname{aryl} \mathrm{R})$ and $\mathrm{Au} / \mathrm{S}-(\operatorname{alkyl} \mathrm{R})),{ }^{37}$ the independence of the tunneling current to the order of the aliphatic and aromatic groups in the interior of the SAMs that we establish for the system described here do not (and are not expected to) hold.

\section{BACKGROUND}

The simplified Simmons equation (eq.1) approximates the attenuation in tunneling current

$$
J(V)=J_{0}(V) e^{-\beta d}=J_{0}(V) 10^{-\frac{\beta d}{2.303}}
$$

density, $J(V)$, through a rectangular barrier composed of an insulating SAM by an exponential term in $\beta d$. Here $d$ represents the width of the barrier (approximated as the length of the molecule comprising the $\mathrm{SAM}$ ), and $\beta$ is the attenuation factor determined by the electrical properties (e.g., the frontier orbital energies) of the molecule. $J_{0}(V)$ is the injection current, and 
describes - among other things - the characteristic of the interfaces between the SAMs and the electrodes. Eq. 1 contains a substantial number of approximations and does not provide a good theoretical basis for analysis of tunneling currents; ${ }^{38}$ it provides, however, a convenient and commonly used method to summarize and parameterize empirical measurements, and we use it here in that spirit. Most studies of charge transport have focused on SAMs comprising either aliphatic or aromatic groups, but have generally not compared them in junctions designed to simplify the interpretation of such comparisons. ${ }^{39-42}$ We previously studied the attenuation factors of aliphatic and aromatic SAMs using junctions with the structure $\mathrm{Met}^{\mathrm{TS}} / \mathrm{A}-\mathrm{R}-\mathrm{H} / / \mathrm{Ga}_{2} \mathrm{O}_{3} / \mathrm{EGaIn}$, where $\mathrm{Met}^{\mathrm{TS}}$ is template-stripped gold or silver, $\mathrm{A}$ is a thiolate $(-\mathrm{S}-)$, acetylene $(-\mathrm{C} \equiv \mathrm{C}-)$, a methylenethiolate $\left(-\mathrm{SCH}_{2}-\right)$ or a carboxylate $\left(-\mathrm{O}_{2} \mathrm{C}-\right)$ group that links ("anchors") organic moieties $\left(\mathrm{R}=\left(\mathrm{CH}_{2}\right)_{\mathrm{n}}\right.$ or $\left.\left(\mathrm{C}_{6} \mathrm{H}_{4}\right)_{\mathrm{m}}\right)$ to the surface of metal electrodes, and EGaIn is eutectic gallium-indium alloy covered by a thin film of gallium oxide); we have characterized this junction in a series of papers. ${ }^{43-47}$

In the previous study involving organic carboxylates $\left(\mathrm{O}_{2} \mathrm{CR}\right),{ }^{44}$ we found that the attenuation factor of $n$-alkanoates $\left(\beta=0.79 \pm 0.02 \AA^{-1}\right)$ is higher than that of oligophenylcarboxylates $\left(\beta=0.60 \pm 0.03 \AA^{-1}\right)$, but the injection current $\left(\log \left|J_{0}(-0.5 \mathrm{~V})\right|=3.5 \pm 0.2\right)$ appears insensitive to the identity of these two types of hydrocarbons and their interfaces with electrodes. The difference in $\beta$ for aliphatic and aromatic carboxylates is in agreement with predictions based on molecular orbital (MO) theory. ${ }^{2,8,48}$ Aromatic molecules are characterized by smaller energy gaps $(\sim 3-5 \mathrm{eV})$ between the highest occupied molecular orbital (HOMO) and the lowest unoccupied molecular orbital (LUMO) than those of aliphatic molecules $(\sim 7 \mathrm{eV})$ of similar length. ${ }^{2,49}$ Furthermore, the HOMO of aromatic molecules aligns more favorably with the Fermi level of electrodes than does that of aliphatic molecules; this alignment, in a SAM-based 
tunneling junction, facilitates charge transport by lowering the effective height of the tunneling barrier. ${ }^{5}$ These differences in the electronic properties of aliphatic and aromatic carboxylates are the basis of the differences in $\beta$ and rates of tunneling. ${ }^{2}$

Charge tunneling through an insulating molecule comprising both aliphatic and aromatic units in the structure of the molecular backbone-what we will call here a "hybrid" molecular system—cannot be described adequately using a simple rectangular barrier. Measurements of charge transport through $\mathrm{Ag}$ or $\mathrm{Au} / \mathrm{SCH}_{2}-($ aromatic $\mathrm{R}) /($ aliphatic $\mathrm{R})-\mathrm{CH}_{2} \mathrm{~S} / \mathrm{Hg}$ junction have been studied. ${ }^{49-52}$ This hybrid structure, however, is problematic for three reasons: i) the noncovalent interface $\left(\mathrm{SAM}_{1} / / \mathrm{SAM}_{2}\right)$ between the SAMs introduces an unknown influence on rates of charge transport in an undefined way. ${ }^{40}$ ii) In order to observe measurable currents, this type of study is restricted to short molecules (e.g., $n$-hexanethiolates) on the $\mathrm{Hg}$ electrode; these junctions short electrically at low voltages $(\leq 0.7 \mathrm{~V}) .{ }^{39}$ iii) The molecular order and film thickness of these SAMs is difficult to determine, especially when subjected to the presence of electrostriction.

\section{EXPERIMENTAL DESIGN}

We used junctions with the structure $\mathrm{Ag}^{\mathrm{TS}} / \mathrm{O}_{2} \mathrm{C}-\mathrm{R}_{1}-\mathrm{R}_{2}-\mathrm{H} / / \mathrm{Ga}_{2} \mathrm{O}_{3} / \mathrm{EGaIn}$ to study charge transport through a linear assembly of polymethylene $\left(\mathbf{C}_{\mathbf{n}}\right)$ and oligophenylene $\left(\mathbf{P} \mathbf{h}_{\mathbf{m}}\right)$ groups. We wished to determine if each group contributes independently to the barrier, whether the order of the $\mathbf{C}_{\mathbf{n}}$ and $\mathbf{P} \mathbf{h}_{\mathbf{m}}$ groups in the junction determines its properties, or whether the effective $\beta$ determined by a plot of $\log |J(V)|$ versus $d$ was not simply related to the values of $\beta$, and the length, of the individual segments. ${ }^{53}$ Specifically, we wished to compare $J(V)$ across junction with structures $\mathrm{Ag}^{\mathrm{TS}} / \mathrm{O}_{2} \mathrm{C}-\mathbf{C}_{\mathbf{n}} \mathbf{P h} \mathbf{h}_{\mathbf{m}}-\mathrm{H} / / \mathrm{Ga}_{2} \mathrm{O}_{3} / \mathrm{EGaIn}$ and $\mathrm{Ag}{ }^{\mathrm{TS}} / \mathrm{O}_{2} \mathrm{C}-\mathbf{P h}_{\mathbf{m}} \mathbf{C}_{\mathbf{n}}-\mathrm{H} / / \mathrm{Ga}_{2} \mathrm{O}_{3} / \mathrm{EGaIn}$ 
junctions $(\mathrm{m}=0,1,2$ and $\mathrm{n}=0,2,4,6,8$; Figure 1$)$. We prepared junctions that differ only in the number and the order of $\mathbf{C}_{\mathbf{n}}$ and $\mathbf{P} \mathbf{h}_{\mathbf{m}}$ units, and compared trends in rates of tunneling transport across these junctions. We designed the junction to keep the interfaces $\left(\mathrm{Ag}^{\mathrm{TS}} / \mathrm{O}_{2} \mathrm{C}\right.$ and $\mathrm{H} / / \mathrm{Ga}_{2} \mathrm{O}_{3}$ ) constant. We use a junction with the interface $\mathrm{Ag}^{\mathrm{TS}} / \mathrm{O}_{2} \mathrm{C}$, because the HOMO in this system is localized on the carboxylate group, and does not delocalize into either the $\mathbf{C}_{\mathbf{n}}$ or $\mathbf{P h} \mathbf{m}$ groups (vide infra). This localization of the HOMO on the anchoring group allows us to keep the $\mathrm{Ag}^{\mathrm{TS}} / \mathrm{O}_{2} \mathrm{C}$ interface constant across the series of molecules examined. There may, however, be structural details that differ at the $\mathrm{H} / / \mathrm{Ga}_{2} \mathrm{O}_{3}$ interface, since we do not have atomic-level control. The similarity in $J_{0}(\mathrm{~V})$ for n-alkanoates and oligophenyl-carboxylates suggests that contributions of the $\mathrm{Ag}{ }^{\mathrm{TS}} / \mathrm{O}_{2} \mathrm{C}$ and $\mathrm{H} / / \mathrm{Ga}_{2} \mathrm{O}_{3}$ interfaces to rates of charge transport are constant across the compounds we have examined, and that differences in interfaces involving aliphatic and aromatic groups are minimal.

This study is based on the carboxylate-containing SAMs $\left(\mathrm{O}_{2} \mathrm{CR}\right)$; other interfaces (especially those based on $\mathrm{SCH}_{2} \mathrm{R}$ groups) can also be used in this type of junction. We concluded previously that replacing $\mathrm{Ag}^{\mathrm{TS}} / \mathrm{SCH}_{2} \mathrm{R}$ with $\mathrm{Ag}^{\mathrm{TS}} / \mathrm{O}_{2} \mathrm{CR}$ in EGaIn-based junctions does not significantly change rates of charge transport. ${ }^{44} \mathrm{SAMs}$ of oligophenyl-thiolates $\left(\mathrm{SPh}_{\mathrm{n}}\right)$ and -methylenethiolates $\left(\mathrm{SCH}_{2} \mathrm{Ph}_{\mathrm{n}}\right)$, and of $\mathrm{O}_{2} \mathrm{CPh}_{\mathrm{n}}$ and $\mathrm{SPh}_{n}$, are, however, not comparable. In a separate study, ${ }^{37}$ we show that the methylene group in $\mathrm{SCH}_{2} \mathrm{Ph}_{\mathrm{n}}$ prevents delocalization of electron density between the oligophenyl $\left(-\mathrm{Ph}_{\mathrm{n}}\right)$ and the conducting electrodes ( $\mathrm{Au}$ and $\left.\mathrm{Ag}\right)$.

\section{RESULTS AND DISCUSSION}

We prepared SAMs starting with commercially available 4-alkyl-oligo(phenylene)-carboxylic acids $\left(\mathbf{O}_{2} \mathbf{C}-\mathbf{P h} \mathbf{h}_{\mathbf{m}} \mathbf{C}_{\mathbf{n}}\right)$ and $\omega$-oligo(phenylene)-alkanoic acids $\left(\mathbf{O}_{2} \mathbf{C}-\mathbf{C}_{\mathbf{n}} \mathbf{P h} \mathbf{h}_{\mathbf{m}}\right)$, and compared their 
rates of charge transport with SAMs of $n$-alkanoate $\left(\mathbf{O}_{2} \mathbf{C}-\mathbf{C}_{\mathbf{n}}\right)$, benzoic acid $\left(\mathbf{O}_{2} \mathbf{C}-\mathbf{P h}\right)$, and biphenyl-4-carboxylate $\left(\mathbf{O}_{2} \mathbf{C}-\mathbf{P h}_{2}\right)$. The preparation of aromatic SAMs on $\mathrm{Ag}^{\mathrm{TS}}$ followed a previously reported literature procedure and is outlined in Supporting Information. ${ }^{44,54,55} \mathrm{We}$ measured and compared $J(\mathrm{~V})$ of $\mathrm{Ag}^{\mathrm{TS}} / \mathbf{O}_{2} \mathbf{C}-\mathbf{P h}_{\mathbf{m}} \mathbf{C}_{\mathbf{n}} / / \mathrm{Ga}_{2} \mathrm{O}_{3} / \mathrm{EGaIn}$ and $\mathrm{Ag}^{\mathrm{TS}} / \mathbf{O}_{\mathbf{2}} \mathbf{C}-\mathbf{C}_{\mathbf{n}} \mathbf{P h}_{\mathbf{m}} / / \mathrm{Ga}_{2} \mathrm{O}_{3} / \mathrm{EGaIn}$ junctions ( $\mathrm{m}=0,1,2$ and $\left.\mathrm{n}=0,2,4,6,8\right)$ over the range of $\pm 0.5 \mathrm{~V}$ as a function of the number of methylene units; we did not observe rectification of current (Figures S1 and S2). The junction measurements of $\mathbf{O}_{2} \mathbf{C}-\mathbf{C}_{\mathrm{n}}, \mathbf{O}_{2} \mathbf{C}-\mathbf{P h} \mathbf{h}_{\mathrm{m}}, \mathbf{O}_{2} \mathbf{C}-\mathbf{C}_{2} \mathbf{P h}$, and $\mathbf{O}_{2} \mathbf{C}-\mathbf{C}_{4} \mathbf{P h}$ were published elsewhere. ${ }^{44,56}$ Values of the log-deviation $\left(\sigma_{\mathrm{log}}\right)$ ranged from 0.1 to 0.3 (corresponding to $\sigma=1.3$ to 2.0 ; see the Supporting information for the details of the data analysis); these values are similar to those measured for $\mathbf{O}_{2} \mathbf{C}-\mathbf{C}_{\mathbf{n}}$ and $\mathbf{O}_{2} \mathbf{C}-\mathbf{P} \mathbf{h}_{\mathbf{m}}$ on $\mathrm{Ag}^{\mathrm{TS}}$. As expected from the Simmons equation, $J(\mathrm{~V})$ decreased exponentially with an increase in the length of the $\mathbf{C}_{\mathbf{n}}$ segments.

\section{Tunneling current is sensitive to the identity of molecular units comprising the}

\section{linear structure of the molecule, but not to the sequence in which they are assembled.}

Figure 2 shows a plot of $\log |J(-0.5 \mathrm{~V})|$ versus the number of methylene groups for these two analogous series. The length of the methylene chain $\left(\mathbf{C}_{\mathbf{n}}\right)$ was estimated in $\AA$; the length of a dimethylene $\left(-\mathrm{CH}_{2} \mathrm{CH}_{2}-; \mathbf{C}_{2}\right)$ unit is approximately $2.54 \AA$. A linear-least square fit for each series $(\mathrm{m}=0,1,2)$ yielded an intercept (at the $y$ axis; coefficient of determination, $R^{2}=0.99$ ), which represents the extrapolated value of the $\log$-current density $\left(\log \left|J_{0}\right|\right)$ when $\mathrm{n}=0$; the slope of the fit yields $\beta$ for the methylene chain (see Table 1). The trends for the isomers $\left(\mathbf{O}_{2} \mathbf{C}-\mathbf{P h}_{\mathbf{m}} \mathbf{C}_{\mathbf{n}}\right.$ versus $\mathbf{O}_{2} \mathbf{C}-\mathbf{C}_{\mathbf{n}} \mathbf{P h} \mathbf{h}_{\mathbf{m}}$ ) are superimposable (Figure 3); that is, the isomeric pairs yield indistinguishable slopes $\left(\beta=0.77-0.78 \AA^{-1}\right.$ when $\mathrm{m}=1$ and $\beta=0.68-0.74 \AA^{-1}$ when $\left.\mathrm{m}=2\right)$ and 
intercepts $\left(\log \left|J_{0}\right|=1.4 \pm 0.2\right.$ for $\mathbf{O}_{\mathbf{2}} \mathbf{C}-\mathbf{P h} \mathbf{C}_{\mathbf{n}}$ versus $\log \left|J_{0}\right|=1.6 \pm 0.2$ for $\mathbf{O}_{\mathbf{2}} \mathbf{C}-\mathbf{C}_{\mathbf{n}} \mathbf{P h} ; \log \left|J_{0}\right|=$ $0.2 \pm 0.2$ for $\mathbf{O}_{\mathbf{2}} \mathbf{C}-\mathbf{P h} \mathbf{C}_{\mathbf{2}} \mathbf{C}_{\mathbf{n}}$ versus $\log \left|J_{0}\right|=0.2 \pm 0.2$ for $\left.\mathbf{O}_{\mathbf{2}} \mathbf{C}-\mathbf{C}_{\mathbf{n}} \mathbf{P} \mathbf{h}_{\mathbf{2}}\right)$.

Comparisons of the trends in Figure 3 indicate that i) the values of $\beta$ for the embedded alkyl segment in $\mathbf{O}_{\mathbf{2}} \mathbf{C}-\mathbf{C}_{\mathbf{n}} \mathbf{P h}\left(\beta=0.78 \pm 0.02 \AA^{-1}\right)$ and for the terminal alkyl chain of $\mathbf{O}_{\mathbf{2}} \mathbf{C}-\mathbf{P h} \mathbf{C}_{\mathbf{n}}$ $\left(\beta=0.77 \pm 0.02 \AA^{-1}\right)$ are indistinguishable from that for $\mathbf{O}_{\mathbf{2}} \mathbf{C}-\mathbf{C}_{\mathbf{n}}\left(\beta=0.80 \pm 0.02 \AA^{-1}\right)$ and alkanethiolates $\left(\beta=0.75 \pm 0.02 \AA^{-1}\right) ;{ }^{28}$ ii) the extrapolated values (when $\left.\mathrm{n}=0\right)$ of $\log \left|J_{0}(-0.5 \mathrm{~V})\right|$ for $\mathbf{O}_{2} \mathbf{C}-\mathbf{P h} \mathbf{h}_{\mathbf{m}} \mathbf{C}_{\mathbf{n}}$ and $\mathbf{O}_{2} \mathbf{C}-\mathbf{C}_{\mathbf{n}} \mathbf{P h} \mathbf{h}_{\mathbf{m}}\left(\mathrm{m}=1\right.$ and 2) are indistinguishable from values of $\mathbf{O}_{2} \mathbf{C}-\mathbf{P h}$ $(\log |J|=1.5 \pm 0.2)$ and $\mathbf{O}_{2} \mathbf{C}-\mathbf{P h}_{2}(\log |J|=0.2 \pm 0.2) .{ }^{44}$ Based on the measurements of $J(V)$ in $\mathrm{Ag}^{\mathrm{TS}} / \mathrm{O}_{2} \mathrm{C}-\mathrm{R}_{1}-\mathrm{R}_{2}-\mathrm{H} / / \mathrm{Ga}_{2} \mathrm{O}_{3} / \mathrm{EGaIn}$ junctions, we draw three conclusions: i) both aromatic and aliphatic units $\left(\mathrm{R}_{1}\right.$ and $\left.\mathrm{R}_{2}\right)$ in SAMs contribute independently but differently to the height of the tunneling barrier; ii) the influences of the $\mathbf{C}_{\mathbf{n}} / / \mathrm{Ga}_{2} \mathrm{O}_{3}$ and $\mathbf{P h} / / \mathrm{Ga}_{2} \mathrm{O}_{3}$ interfaces on the rates of charge transport are indistinguishable and remain constant across the series examined; and iii) the tunneling current is sensitive to the length of the individual units (or the number of methylene and phenylene units) in SAMs, but not to the sequence in which they are connected.

We compared $J(\mathrm{~V})$ of three structural isomers $\mathbf{O}_{2} \mathbf{C}-\mathbf{C}_{4} \mathbf{P h}(\log |J|=-0.24 \pm 0.09)$, $\mathbf{O}_{2} \mathbf{C}-\mathbf{C}_{2} \mathbf{P h C} \mathbf{C}_{2}(\log |J|=-0.2 \pm 0.2)$, and $\mathbf{O}_{2} \mathbf{C}-\mathbf{P h C} \mathbf{C}_{4}(\log |J|=-0.3 \pm 0.1)$ at $-0.5 \mathrm{~V}$ (Figure 4). Values of $J(V)$ across these three junctions were indistinguishable: that is, permuting the positions of phenylene $(\mathbf{P h})$ and dimethylene $\left(\mathbf{C}_{2}\right)$ groups along the backbone of the SAM does not alter the overall rate of charge transport across the junctions. A similar trend in the series of $\mathbf{O}_{2} \mathbf{C}-\mathbf{P h}_{\mathbf{n}} \mathbf{C}_{2} \mathbf{P h} \mathbf{h}_{\mathbf{m}}(\mathrm{n}+\mathrm{m}=2 ; \mathrm{n}, \mathrm{m}=0,1,2)$, where we compared $J(-0.5 \mathrm{~V})$ of $\mathbf{O}_{2} \mathbf{C}-\mathbf{P h} \mathbf{C}_{2} \mathbf{C}_{\mathbf{2}}$ $\left(\log |J|=-0.6 \pm 0.3 ;\right.$ Figure S3), $\mathbf{O}_{2} \mathbf{C}-\mathbf{P h} \mathbf{C}_{2} \mathbf{P h}(\log |J|=-0.4 \pm 0.1)$ and $\mathbf{O}_{2} \mathbf{C}-\mathbf{C}_{2} \mathbf{P h} \mathbf{h}_{2}(\log |J|=-0.6$ \pm 0.3 ; Figure S4), provides further evidence that permuting $\mathrm{CH}_{2}$ and $\mathrm{C}_{6} \mathrm{H}_{4}$ groups in the junction 
does not influence $J(V)$ in these series. Based on these observations, we found that the current density of the $\mathrm{Ag}{ }^{\mathrm{TS}} / \mathrm{O}_{2} \mathrm{C}-\mathrm{R}_{1}-\mathrm{R}_{2}-\mathrm{H} / / \mathrm{Ga}_{2} \mathrm{O}_{3} / \mathrm{EGaIn}$ junctions can be described by eq. 2 , where

$$
J(V)=J_{0}(V) e^{-\left(\beta_{1} d_{1}+\beta_{2} d_{2}\right)}
$$

$\beta_{i}$ and $d_{i}$ are the parameters describing the attenuation of the tunneling current through a rectangular tunneling barrier, with width $d$ and a height related to the attenuation factor $\beta$. $J_{0}$ is the hypothetical current density of $\mathrm{Ag}^{\mathrm{TS}} / \mathrm{O}_{2} \mathrm{C}-\mathrm{R}_{1}-\mathrm{R}_{2}-\mathrm{H} / / \mathrm{Ga}_{2} \mathrm{O}_{3} / \mathrm{EGaIn}$ with $d_{1}=d_{2}=0$, but retaining the chemical and electronic characteristics of the $\mathrm{Ag}^{\mathrm{TS}} / \mathrm{O}_{2} \mathrm{C}$ and $\mathrm{H} / / \mathrm{Ga}_{2} \mathrm{O}_{3}$ interfaces.

\section{Large orbital overlap between molecular units comprising the SAM influences the} topography of the barrier of the SAM. We changed the extent of electronic conjugation between the two phenylene rings in the structure of $\mathbf{O}_{2} \mathbf{C}-\mathbf{P h C H}_{2} \mathbf{C H}_{2} \mathbf{P h}$ by replacing dimethylene $\left(-\mathrm{CH}_{2} \mathrm{CH}_{2}-\right)$ with vinylene $\left(-\mathrm{CH}=\mathrm{CH}-; \mathbf{O}_{2} \mathbf{C}-\mathbf{P h C H}=\mathbf{C H P h}\right)$ or acetylene $(-\mathrm{C} \equiv \mathrm{C}-$; $\left.\mathbf{O}_{2} \mathbf{C}-\mathbf{P h C} \equiv \mathbf{C P h}\right)$. Although these three molecules have similar lengths $(\sim 12.4 \AA)$, the rates of charge transport through conjugated $\mathbf{O}_{2} \mathbf{C}-\mathbf{P h C H}=\mathbf{C H P h}(\log |J|=0.4 \pm 0.2)$ and $\mathbf{O}_{\mathbf{2}} \mathbf{C}-\mathbf{P h C} \equiv \mathbf{C P h}$ $(\log |J|=0.5 \pm 0.08)$ molecules are higher than that of $\mathbf{O}_{2} \mathbf{C}-\mathbf{P h C} \mathbf{C H}_{2} \mathbf{C H}_{2} \mathbf{P h}(\log |J|=-0.4 \pm 0.1)$ by factors of 6-8 (at $-0.5 \mathrm{~V}$; Figure 5 ). We estimated the values of the attenuation factor $\left(\beta_{\text {calc }}\right)$ for the units $-\mathrm{PhCH}=\mathrm{CHPh}-$ and $-\mathrm{PhC} \equiv \mathrm{CPh}-$ using eq. 1 ; the estimates for these two units are indistinguishable $\left(\beta_{\text {calc }} \sim 0.36 \AA^{-1}\right)$ and lower than the values estimated for oligophenylene ( $\beta_{\exp }=$ $\left.0.60 \pm 0.03 \AA^{-1}\right)$ and polymethylene $\left(\beta_{\exp }=0.79 \pm 0.02 \AA^{-1}\right)$.

We performed DFT calculation (B3LYP/6-31G+(d, p)) to estimate the HOMO energy of the anionic form (e.g., $\left.\left[{ }^{-} \mathrm{O}_{2} \mathrm{C}-\mathrm{R}\right]\right)$ of these three molecules, since they form SAMs in ionic contacts with the surface of $\mathrm{Ag} / \mathrm{AgO} \times$. While $\left[{ }^{-} \mathbf{O}_{2} \mathbf{C}-\mathbf{P h C H}=\mathbf{C H P h}\right]$ and $\left[{ }^{-} \mathbf{O}_{2} \mathbf{C}-\mathbf{P h C} \equiv \mathbf{C P h}\right]$ have a similar HOMO energy (-1.90 eV), the average of the HOMO energy of [ $\left.{ }^{-} \mathbf{O}_{2} \mathbf{C}-\mathbf{P h C} \mathbf{H}_{2} \mathbf{C H}_{2} \mathbf{P h}\right]$ 
$(-1.67 \mathrm{eV})$ is higher. The calculations also indicate that i) the dihedral angle between the two phenylene (Ph) rings in the structure of $\left[{ }^{-} \mathbf{O}_{2} \mathbf{C}-\mathbf{P h C} \equiv \mathbf{C P h}\right]$ has a minimal effect on the energy of the HOMO $\left(\Delta \mathrm{E} \leq 0.05 \mathrm{eV}\right.$; Table S1); ii) the HOMO of [- $\left.{ }_{2} \mathrm{C}-\mathrm{R}\right]$ appears to be localized on the carboxylate group. There is an orbital node on the carbon of the carboxylate group $\left(\left[{ }^{-} \mathrm{O}_{2} \underline{C}-\mathrm{R}\right]\right)$, which might limit the delocalization of $p$ orbitals between the aryl groups and the negatively charged carboxylate group (and perhaps restricts, the delocalization of electron density of aryl carboxylate-bound silver (e.g., $\mathrm{Ag} / \mathrm{O}_{2} \mathrm{C}-\mathrm{R}$ ) across the $\mathrm{Ag} / \mathrm{O}_{2} \mathrm{C}$ interface). We thus attribute the indistinguishable $J(\mathrm{~V})$ of $\mathbf{O}_{2} \mathbf{C}-\mathbf{P h C H}=\mathbf{C H P h}$ and $\mathbf{O}_{2} \mathbf{C}-\mathbf{P h C} \equiv \mathbf{C P h}$ to the similarity in the heights of the tunneling barrier. These results suggest that the delocalization of $\pi$ electrons between the unsaturated functional groups in $-\mathrm{PhCH}=\mathrm{CHPh}-$ and $-\mathrm{PhC} \equiv \mathrm{CPh}-$, decreases the overall height of the barrier and increases the rates of charge transport relative to that of $-\mathrm{PhCH}_{2} \mathrm{CH}_{2} \mathrm{Ph}$ - and saturated alkanes with similar widths.

\section{$J(V)=J_{0}(V) \exp \left(-\beta_{1} d_{1}-\beta_{2} d_{2}\right)$ can be derived theoretically using a multi-barrier}

model and a tight-binding model. To understand the condition required for eq. 2 to approximate the rate of charge transport across junctions of the structure $\mathrm{Ag}^{\mathrm{TS}} / \mathrm{O}_{2} \mathrm{C}-\mathrm{R}_{1}-\mathrm{R}_{2}-\mathrm{H} / / \mathrm{Ga}_{2} \mathrm{O}_{3} / \mathrm{EGaIn}$, we modeled the experimental system using two theoretical approaches in the framework of Landauer theory: (i) a multi-barrier model, using a wavefunction method; (ii) a tight-binding model, using a Green's function method. (The Supporting Information details the mathematical derivations of eq. 2 and the corresponding assumptions.) Landauer theory has been used to describe tunneling at the single-molecule level $;{ }^{57}$ here we use this theory to approximate the current density, $J$, across a SAM. We assume that charge transport is through-bond (i.e. the charge travels along the backbone of the molecules) and neglect lateral, through-space, or 
intermolecular charge transport. The current density $J$ across the assembly of $N$ molecules in an area $A$ can be described by eq. 3 , where $h$ is Planck's constant, $e$ is the elementary charge, and

$$
J=\frac{N}{A} \frac{2 e^{2} V}{h} T\left(E_{F}\right)
$$

$T\left(E_{F}\right)$ is the transmission function at the Fermi level. Eq. 3 indicates that $J$ is proportional to $T\left(E_{F}\right)$.

First, we used a multi-barrier model (approach i) to model charge transport through the SAM and compute the transmission functions. When an electron passes through molecular series junctions, it tunnels across the individual barriers formed by the electrodes, by the interfaces, and by the $\mathrm{R}_{1}$ and $\mathrm{R}_{2}$ units. From the experimental observations, we conclude that the interactions between the $R_{1}$ and $R_{2}$ units do not significantly influence their electronic properties (and thus the values of $\beta_{1} d_{1}$ and $\beta_{2} d_{2}$ ), and that the other properties of the junction (e.g., the contribution of the interfaces between the SAMs and the electrodes) remain constant across all the compounds examined. Within this framework, we can calculate the transmission function in eq. 3 and derive the form of eq. 2 with $\beta_{1}=\frac{2 \sqrt{2 m V_{1}}}{\hbar}$ and $\beta_{2}=\frac{2 \sqrt{2 m V_{2}}}{\hbar}$, where $V_{i}$ is the height of the potential barriers (i.e., the difference between the HOMO of the molecular units and the Fermi level of the electrodes). The variables and constants $N, A, e, V$, and $h$ are absorbed in $J_{0}$, which is a function of $V$.

The second approach—which uses a tight-binding model and Green's function-is more general than the multi-barrier model and allows us to consider coherent inelastic tunneling, ${ }^{58}$ many-body interactions, ${ }^{59}$ light-driven transport, ${ }^{14,60}$ and the influence of the electrodes by introducing self-energy. In previous work, Frisbie, $,{ }^{38,48} \mathrm{Chen},{ }^{19}$ and Ratner, ${ }^{53}$ modeled the rate of 
charge transport across molecular junctions, and included the considerations of orbital overlap between the molecular units and the electrodes, within the framework of an approach based on

Green's function. ${ }^{61,62}$ Here, we adopt the same assumptions (used in the multi-barrier model): the influence on rates of charge transport from the electrodes is constant, and each molecular unit (e.g., $\mathrm{R}_{1}$ and $\mathrm{R}_{2}$ ) is modeled as a form of a molecular orbital that only interacts electrically with neighboring units. We derive eq. 2 with $\beta_{1}=\frac{2 N_{1}}{d_{1}} \ln \left|\frac{E_{F}-\epsilon_{1}}{t_{1}}\right|$ and $\beta_{2}=\frac{2 N_{2}}{d_{2}} \ln \left|\frac{E_{F}-\epsilon_{2}}{t_{2}}\right|$, where $N_{i}$ is the number of $R_{i}$ units, $\epsilon_{i}$ is the HOMO energy of $R_{i}$ units, and $t_{i}$ is the coupling between $R_{i}$ units. This result indicates that increasing the gap $\left(\left|E_{F}-\epsilon_{n}\right|\right)$ between the HOMO of the individual units and the Fermi level of the electrodes increases the value of $\beta$, and that large electronic coupling between the $\mathrm{R}_{1}$ and $\mathrm{R}_{2}$ units (as a form of delocalization of molecular orbitals) decreases the value of $\beta$.

\section{CONCLUSION}

This paper describes experiments that test the relationship of tunneling current to the order of aromatic and aliphatic groups in junctions of the form $\mathrm{Ag}^{\mathrm{TS}} / \mathrm{O}_{2} \mathrm{C}-\mathrm{R}_{1}-\mathrm{R}_{2}-\mathrm{H} / / \mathrm{Ga}_{2} \mathrm{O}_{3} / \mathrm{EGaIn}$ (where $\mathrm{R}_{1}, \mathrm{R}_{2}=\left(\mathrm{CH}_{2}\right)_{\mathrm{n}}$ and $\left(\mathrm{C}_{6} \mathrm{H}_{4}\right)_{\mathrm{m}}$ ). The experiments are designed to make the contributions from the interfaces to the rates of tunneling constant; that is, the electronic characteristics of the $\mathrm{Ag}^{\mathrm{TS}} / \mathrm{O}_{2} \mathrm{C}$ and $\mathrm{H} / / \mathrm{Ga}_{2} \mathrm{O}_{3}$ interfaces can be considered to be approximately constant across all the compounds studied. DFT calculations show that the HOMO of these junctions is localized on the carboxylate group and does not delocalize into the aryl or alkyl groups.

In the context of experiments in which we consider the $\mathrm{Ag} / \mathrm{O}_{2} \mathrm{CR}$ and $\mathrm{H} / / \mathrm{Ga}_{2} \mathrm{O}_{3}$ interfaces to be constant, we examined the sensitivity of tunneling currents to the permutation of $R_{1}$ and $R_{2}$ in the junction, and derived a form of the modified Simmons equation (eq. 2), 
$J(V)=J_{0}(V) \exp \left(-\beta_{1} d_{1}-\beta_{2} d_{2}\right)$, to describe the rate of charge transport across these junctions. The key experimental finding is that the tunneling current is independent of the order of the aliphatic and aromatic groups in junctions of the form $\mathrm{Ag}^{\mathrm{TS}} / \mathrm{O}_{2} \mathrm{C}-\mathrm{R}_{1}-\mathrm{R}_{2}-\mathrm{H} / / \mathrm{Ga}_{2} \mathrm{O}_{3} / \mathrm{EGaIn}$. Using a potential barrier model that explicitly assumes constant contributions to rates of tunneling from the interfaces between the SAMs and the electrodes, we found that $\left(\mathrm{CH}_{2}\right)_{\mathrm{n}}$ and $\left(\mathrm{C}_{6} \mathrm{H}_{4}\right)_{\mathrm{m}}$ segments contribute independently but differently to the shape of the tunneling barrier, and that the values of $\beta$ for $\left(\mathrm{CH}_{2}\right)_{\mathrm{n}}$ and $\left(\mathrm{C}_{6} \mathrm{H}_{4}\right)_{\mathrm{m}}$ are independent of the order in which they are assembled. ${ }^{48} \mathrm{We}$ expect this conclusion to hold only when the molecular units $(\mathrm{R})$ being considered are isolated electronically from strong interactions with the electrodes.

These conclusions are important in understanding the relationship between the energetic topography of the tunneling barrier and the rate of charge transport by tunneling across it, and in designing tunneling barriers. We conclude from these studies (at least for SAMs comprising mixture of simple aliphatic and aromatic groups) that the value of $\beta$ for each type of groups is constant and independent of its neighboring groups, and also independent of the bottom and top junctions, since these aromatic and aliphatic groups make independent contributions to the tunneling barrier. The design of a barrier for a potential combination of overall $\beta$ and $J_{0}$ is more a question of the ease of synthesis of the groups than of the particular order in which they are assembled.

We caution that these conclusions rest on data from a particularly simple system, and may not hold if, for example, unsaturated groups can interact across short oligomethylene linkers, or for system where large, embedded dipoles interact with one another. In the region of low applied bias $(\leq 0.5 \mathrm{~V})$, the measurements of tunneling across $\mathrm{Ag}^{\mathrm{TS}} / \mathrm{O}_{2} \mathrm{C}-\mathrm{R}_{1}-\mathrm{R}_{2}-\mathrm{H} / / \mathrm{Ga}_{2} \mathrm{O}_{3} / E G a I n$ confirm (as suggested by Joachim ${ }^{26}$ ) that an expression of the form of eq. 2 is valid when $R_{1}$ and 
$\mathrm{R}_{2}$ contribute independently to the shape of the tunneling barrier, and the other properties of the junction (e.g., the contributions of the $\mathrm{Ag}^{\mathrm{TS}} / \mathrm{O}_{2} \mathrm{C}$ and $\mathrm{H} / / \mathrm{Ga}_{2} \mathrm{O}_{3}$ interfaces) remain constant; in this circumstance, the rate of charge transport is insensitive to the sequence in which the units $R_{1}$ and $\mathrm{R}_{2}$ are assembled. When the sequence, or the chemical interactions between the molecular units in the junction or at the SAM-metal interfaces, induces significant changes in the electronic structure of the individual units or their assembly (through, for example, the delocalization of electron density in $-\mathrm{PhCH}=\mathrm{CHPh}-$ and $-\mathrm{PhC} \equiv \mathrm{CPh}-$ ), we detect changes in both the topography of the tunneling barrier and the rate of charge transport.

\section{ASSOCIATED CONTENT}

Supporting information

Detailed experimental procedure, histograms of current densities, summary of junction measurements, and the derivations of the modified Simmons equation (eq. 2) based on a multibarrier model and a Green's function approach. This material is available free of charge via the Internet at http://pubs.acs.org.

\section{AUTHOR INFORMATION}

Corresponding Author

hrabitz@princeton.edu (H.R.),gwhitesides@gmwgroup.harvard.edu (G.M.W.) Notes

L.-Y.H. and C.M.B. contributed equally to this work. The authors declare no competing financial interest. 


\section{ACKNOWLEDGMENTS}

The work containing experimental work on synthesis of materials and measurements of charge transport (Harvard) was supported as part of the Center for Bio-Inspired Energy Science, an Energy Frontier Research Center funded by the U.S. Department of Energy, Office of Science, Basic Energy Sciences under Award \# DE-SC0000989. The development of the theory (Princeton) was supported by the NSF (Grant Number CHE-1058644), ARO (Grant Number W911NF-13-1-0237) and PPST grants. The DOE grant also supported the salaries for K.-C.L. and C.M.B.

\section{REFERENCES}

(1) Cahen, D.; Kahn, A. Adv. Mater. 2003, 15, 271.

(2) Salomon, A.; Cahen, D.; Lindsay, S.; Tomfohr, J.; Engelkes, V. B.; Frisbie, C. D. Adv. Mater. 2003, 15, 1881.

(3) McCreery, R. L. Chem. Mater. 2004, 16, 4477.

(4) Beebe, J. M.; Kim, B.; Gadzuk, J. W.; Daniel Frisbie, C.; Kushmerick, J. G. Phys. Rev. Lett. 2006, 97, 026801.

(5) Beebe, J. M.; Kim, B.; Frisbie, C. D.; Kushmerick, J. G. ACS Nano 2008, 2, 827.

(6) Ho Choi, S.; Kim, B.; Frisbie, C. D. Science 2008, 320, 1482.

(7) Hsu, L.-Y.; Jin, B.-Y. Chem. Phys. 2009, 355, 177.

(8) McCreery, R. L.; Bergren, A. J. Adv. Mater. 2009, 21, 4303.

(9) Hines, T.; Diez-Perez, I.; Hihath, J.; Liu, H.; Wang, Z.-S.; Zhao, J.; Zhou, G.;

Müllen, K.; Tao, N. J. Am. Chem. Soc. 2010, 132, 11658.

(10) Mujica, V.; Kemp, M.; Ratner, M. A. J. Chem. Phys. 1994, 101, 6849.

(11) Nitzan, A. Annu. Rev. Phys. Chem. 2001, 52, 681.

(12) Fracasso, D.; Valkenier, H.; Hummelen, J. C.; Solomon, G. C.; Chiechi, R. C. J. Am. Chem. Soc. 2011, 133, 9556.

(13) Guedon, C. M.; Valkenier, H.; Markussen, T.; Thygesen, K. S.; Hummelen, J. C.; van der Molen, S. J. Nat. Nanotechnol. 2012, 7, 305. 
(14) Hsu, L.-Y.; Rabitz, H. Phys. Rev. Lett. 2012, 109, 186801.

(15) Aradhya, S. V.; Venkataraman, L. Nat. Nanotechnol. 2013, 8, 399.

(16) Hsu, L.-Y.; Li, E. Y.; Rabitz, H. Nano Lett. 2013, 13, 5020.

(17) Tan, S. F.; Wu, L.; Yang, J. K. W.; Bai, P.; Bosman, M.; Nijhuis, C. A. Science 2014, 343, 1496.

(18) Hsu, L.-Y.; Wu, N.; Rabitz, H. J. Phys. Chem. Lett. 2014, 5, 1831.

(19) Huang, M.-J.; Hsu, L.-Y.; Fu, M.-D.; Chuang, S.-T.; Tien, F.-W.; Chen, C.-h. J. Am. Chem. Soc. 2014, 136, 1832.

(20) Datta, S. Electronic Transport in Mesoscopic Systems; Cambridge University Press, 1995.

(21) Datta, S. Quantum Transport: Atom to Transistor; Cambridge University Press, 2013.

(22) Lundstrom, M. Fundamentals of Carrier Transport; Cambridge University Press, 2009.

(23) Di Ventra, M. Electrical Transport in Nanoscale Systems; Cambridge University Press, 2008.

(24) Beenakker, C. W. J.; van Houten, H. Solid State Phys. 1991, 44, 1.

(25) Joachim, C.; Gimzewski, J. K.; Aviram, A. Nature 2000, 408, 541.

(26) Magoga, M.; Joachim, C. Phys. Rev. B 1999, 59, 16011.

(27) Weiss, E. A.; Kaufman, G. K.; Kriebel, J. K.; Li, Z.; Schalek, R.; Whitesides, G. M. Langmuir 2007, 23, 9686.

(28) Simeone, F. C.; Yoon, H. J.; Thuo, M. M.; Barber, J. R.; Smith, B.; Whitesides, G. M. J. Am. Chem. Soc. 2013, 135, 18131.

(29) Nijhuis, C. A.; Reus, W. F.; Barber, J. R.; Whitesides, G. M. J. Phys. Chem. C 2012, 116, 14139.

(30) Yuan, L.; Jiang, L.; Zhang, B.; Nijhuis, C. A. Angew. Chem. Int. Ed. 2014, 53, 3377 .

(31) Yuan, L.; Jiang, L.; Thompson, D.; Nijhuis, C. A. J. Am. Chem. Soc. 2014, 136, 6554.

(32) Wimbush, K. S.; Fratila, R. M.; Wang, D.; Qi, D.; Liang, C.; Yuan, L.; Yakovlev, N.; Loh, K. P.; Reinhoudt, D. N.; Velders, A. H.; Nijhuis, C. A. Nanoscale 2014, 6, 11246. 
(33) Barber, J. R.; Yoon, H. J.; Bowers, C. M.; Thuo, M. M.; Breiten, B.; Gooding, D. M.; Whitesides, G. M. Chem. Mater. 2014, 26, 3938.

(34) Jiang, L.; Sangeeth, C. S. S.; Wan, A.; Vilan, A.; Nijhuis, C. A. J. Phys. Chem. C 2014.

(35) Sangeeth, C. S. S.; Wan, A.; Nijhuis, C. A. J. Am. Chem. Soc. 2014, 136, 11134.

(36) Zhang, Y.; Zhao, Z.; Fracasso, D.; Chiechi, R. C. Isr. J. Chem. 2014, 54, 513.

(37) Bowers, C. M.; Rappoport, D.; Baghbanzadeh, M.; Simeone, F. C.; Liao, K.-C.;

Semenov, S.; Zaba, T.; Cyganik, P.; Aspuru-Guzik, A.; Whitesides, G. M., Submitted.

(38) Engelkes, V. B.; Beebe, J. M.; Frisbie, C. D. J. Am. Chem. Soc. 2004, 126, 14287.

(39) Haag, R.; Rampi, M. A.; Holmlin, R. E.; Whitesides, G. M. J. Am. Chem. Soc.

1999, 121,7895 .

(40) Tran, E.; Grave, C.; Whitesides, G. M.; Rampi, M. A. Electrochim. Acta 2005, 50, 4850.

(41) Masillamani, A. M.; Crivillers, N.; Orgiu, E.; Rotzler, J.; Bossert, D.; Thippeswamy, R.; Zharnikov, M.; Mayor, M.; Samorì, P. Chem. Euro. J. 2012, 18, 10335.

(42) Bora, A.; Pathak, A.; Liao, K.-C.; Vexler, M. I.; Kuligk, A.; Cattani-Scholz, A.; Meinerzhagen, B.; Abstreiter, G.; Schwartz, J.; Tornow, M. Appl. Phys. Lett. 2013, 102, 241602.

(43) Yoon, H. J.; Liao, K.-C.; Lockett, M. R.; Kwok, S. W.; Baghbanzadeh, M.;

Whitesides, G. M. J. Am. Chem. Soc. 2014, 136, 17155.

(44) Liao, K.-C.; Yoon, H. J.; Bowers, C. M.; Simeone, F. C.; Whitesides, G. M. Angew. Chem. Int. Ed. 2014, 53, 3889.

(45) Bowers, C. M.; Liao, K.-C.; Yoon, H. J.; Rappoport, D.; Baghbanzadeh, M.; Simeone, F. C.; Whitesides, G. M. Nano Lett. 2014, 14, 3521.

(46) Baghbanzadeh, M.; Simeone, F. C.; Bowers, C. M.; Liao, K.-C.; Thuo, M.;

Baghbanzadeh, M.; Miller, M. S.; Carmichael, T. B.; Whitesides, G. M. J. Am. Chem. Soc. 2014, 136, 16919.

(47) Bowers, C. M.; Liao, K. C.; Zaba, T.; Rappoport, D.; Baghbanzadeh, M.; Breiten, B.; Krzykawska, A.; Cyganik, P.; Whitesides, G. M. ACS Nano 2015, 9, 1471.

(48) Beebe, J.; Kim, B.; Gadzuk, J.; Daniel Frisbie, C.; Kushmerick, J. Phys. Rev. Lett. 2006, 97, 026801. 
(49) Holmlin, R. E.; Haag, R.; Chabinyc, M. L.; Ismagilov, R. F.; Cohen, A. E.;

Terfort, A.; Rampi, M. A.; Whitesides, G. M. J. Am. Chem. Soc. 2001, 123, 5075.

(50) Grave, C.; Risko, C.; Shaporenko, A.; Wang, Y.; Nuckolls, C.; Ratner, M. A.;

Rampi, M. A.; Zharnikov, M. Adv. Funct. Mater. 2007, 17, 3816.

(51) Querebillo, C. J.; Terfort, A.; Allara, D. L.; Zharnikov, M. J. Phys. Chem. C 2013, $117,25556$.

(52) Holmlin, R. E.; Ismagilov, R. F.; Haag, R.; Mujica, V.; Ratner, M. A.; Rampi, M. A.; Whitesides, G. M. Angew. Chem. Int. Ed. 2001, 40, 2316.

(53) Mirjani, F.; Thijssen, J. M.; Whitesides, G. M.; Ratner, M. A. ACS Nano 2014, 8, 12428 .

(54) Tao, Y. T.; Lee, M. T.; Chang, S. C. J. Am. Chem. Soc. 1993, 115, 9547.

(55) Tao, Y.-T.; Hietpas, G. D.; Allara, D. L. J. Am. Chem. Soc. 1996, 118, 6724.

(56) Liao, K. C.; Bowers, C. M.; Yoon, H. J.; Whitesides, G. M. J. Am. Chem. Soc. 2015, 137,3852 .

(57) Nitzan, A.; Ratner, M. A. Science 2003, 300, 1384.

(58) Galperin, M.; Ratner, M. A.; Nitzan, A. J. Phys. Condens. Matter 2007, 19, 103201.

(59) Meir, Y.; Wingreen, N. S.; Lee, P. A. Phys. Rev. Lett. 1991, 66, 3048.

(60) Hsu, L.-Y.; Xie, D.; Rabitz, H. J. Chem. Phys. 2014, 141, 124703.

(61) Landauer, R. IBM J. Res. Dev. 1957, 1, 223.

(62) Ness, H. J. Phys. Condens. Matter 2006, 18, 6307. 
Figure 1. (a) Schematic representation of molecular series tunneling junctions with the structures $\mathrm{Ag}^{\mathrm{TS}} / \mathrm{A}-\mathrm{R}_{1}-\mathrm{R}_{2}-\mathrm{T} / / \mathrm{Ga}_{2} \mathrm{O}_{3} / \mathrm{EGaIn}$ and $\mathrm{Ag}^{\mathrm{TS}} / \mathrm{A}-\mathrm{R}_{2}-\mathrm{R}_{1}-\mathrm{T} / / \mathrm{Ga}_{2} \mathrm{O}_{3} / \mathrm{EGaIn}$; the difference between these two junctions is the position of $R_{1}$ and $R_{2}$ in the junctions. The organic insulating layer (A- $\left.R_{2}-R_{1}-T\right)$ consists of four components connected in series: an anchoring group A, two groups $R_{1}$ and $R_{2}$ that are aliphatic and aromatic, and a terminal group $T$. The layer is sandwiched by two electrodes $\left(\mathrm{Ag}^{\mathrm{TS}}\right.$ and $\left.\mathrm{Ga}_{2} \mathrm{O}_{3} / \mathrm{EGaIn}\right)$, where the anchoring group $\mathrm{A}$ is chemically bound to the bottom template-stripped silver electrode $\left(\mathrm{Ag}^{\mathrm{TS}}\right)$ and the terminal group $\mathrm{T}$ is in van der Waals contact with the top $\mathrm{Ga}_{2} \mathrm{O}_{3} / \mathrm{EGaIn}$ electrode. This model explicitly assumes contributions to rates of tunneling from the anchoring group $\mathrm{A}$, the terminal group $\mathrm{T}$, and the $\mathrm{Ag}^{\mathrm{TS}} / \mathrm{A}$ and $\mathrm{T} / / \mathrm{Ga}_{2} \mathrm{O}_{3}$ interfaces to be constant. (b) We analyze these junctions using a multibarrier model, where the HOMO energy of each unit determines the effective height $(\Delta \mathrm{E})$ of the corresponding barrier; $E_{\mathrm{F}}$ is the Fermi level of the electrodes. Here, $\mathrm{R}_{1}$ represents an aromatic group which has a lower barrier than that of aliphatic groups $\left(\mathrm{R}_{2}\right)$. We assume that the barrier of each component, including $\mathrm{R}_{1}$ and $\mathrm{R}_{2}$ and the interface between molecules and electrodes $\left(\mathrm{T} / / \mathrm{Ga}_{2} \mathrm{O}_{3}\right.$ and $\left.\mathrm{Ag} / \mathrm{A}\right)$, is independent of the sequence in which they are assembled and contributes to the overall shape of the barrier.

a.
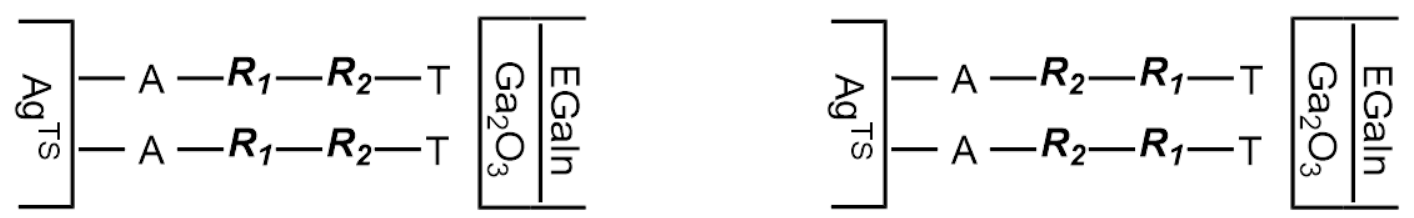

b.

Molecular Series-Tunneling Junction

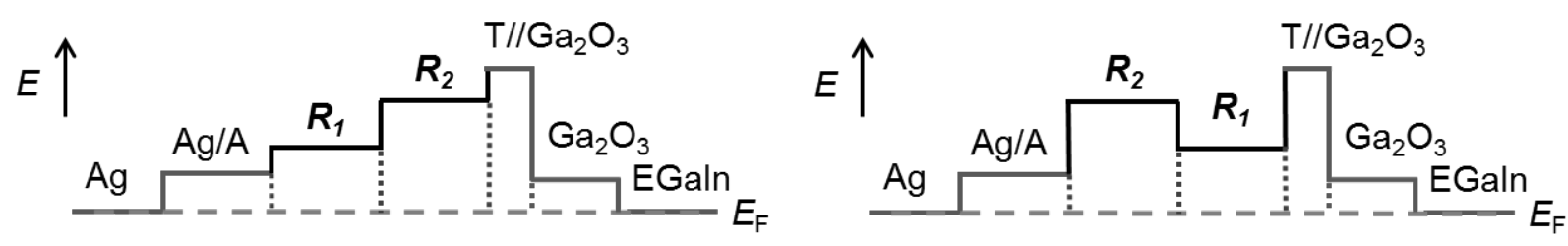


Figure 2. Plots of $\log$-current density $(\log |J|)$ against the number of methylene units for junctions comprising of (a) $\mathbf{O}_{2} \mathbf{C}-\mathbf{P h} \mathbf{h}_{\mathbf{m}} \mathbf{C}_{\mathbf{n}}$ and (b) $\mathbf{O}_{\mathbf{2}} \mathbf{C}-\mathbf{C}_{\mathbf{n}} \mathbf{P h} \mathbf{h}_{\mathbf{m}}(\mathrm{m}=0,1,2$ and $\mathrm{n}=0,2,4,6,8)$ at $-0.5 \mathrm{~V}$. The results of electrical measurement are inserted in the figure. The length of the methylene chain $\left(\mathbf{C}_{\mathbf{n}}\right)$ was estimated in $\AA$; the length of an ethylene $\left(\mathbf{C}_{2}\right)$ unit is approximately $2.54 \AA$. Intervals $(\Delta \log |J(V)|=1.2-1.5)$ between the slopes reveal the contributions of an additional phenylene unit to the rate of charge transport across the junctions.

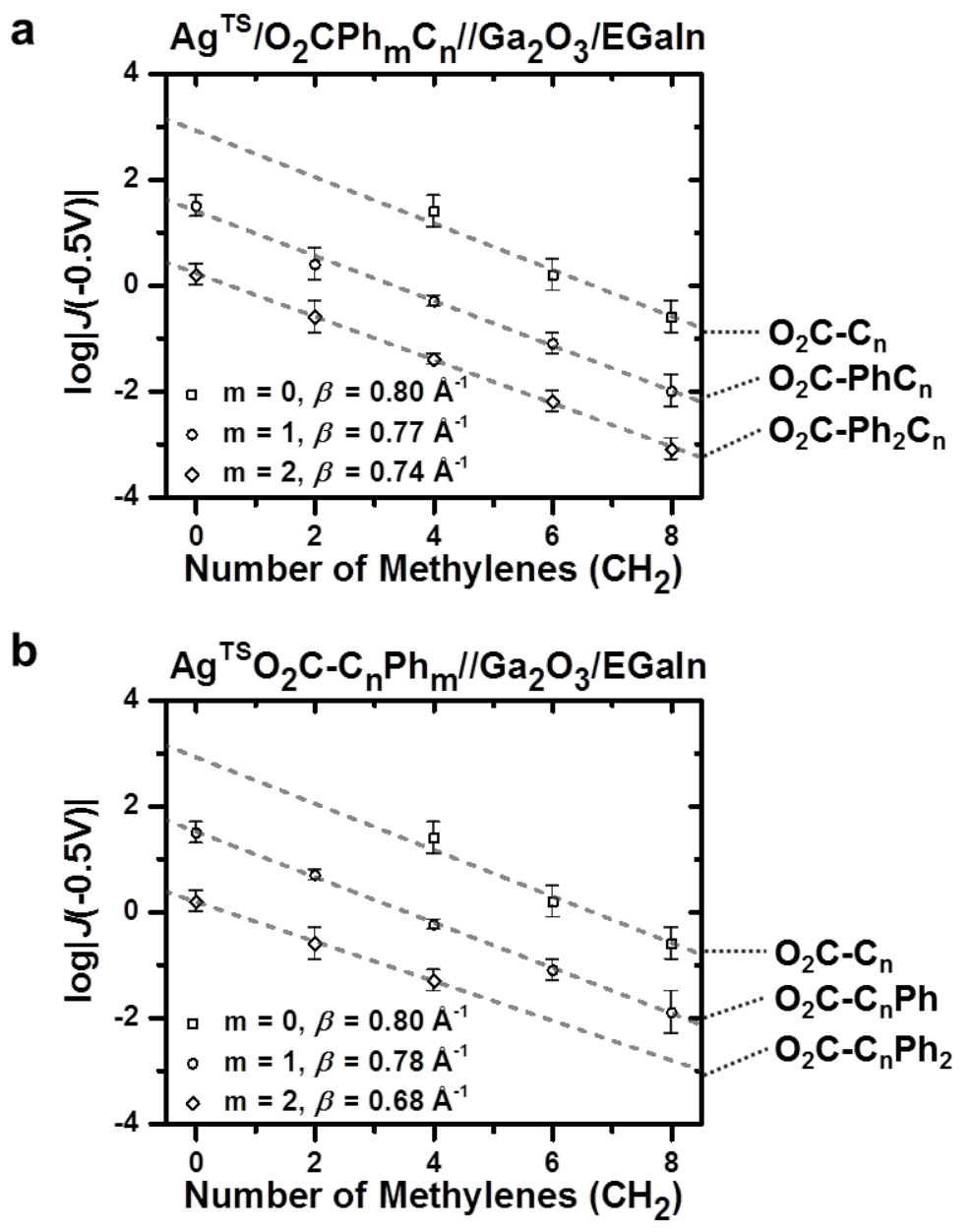


Figure 3. Plots of log-current density $(\log |J|)$ against the number of $\mathrm{CH}_{2}$ at $-0.5 \mathrm{~V}$. The linearleast square fits generate slopes for (a) $\mathbf{O}_{2} \mathbf{C}-\mathbf{C}_{\mathbf{n}} \mathbf{P h}$ (solid line) and $\mathbf{O}_{2} \mathbf{C}-\mathbf{P h C} \mathbf{C}_{\mathbf{n}}$ (dotted line), and for (b) $\mathbf{O}_{2} \mathbf{C}-\mathbf{C}_{\mathbf{n}} \mathbf{P h} \mathbf{h}_{2}$ (solid line) and $\mathbf{O}_{2} \mathbf{C}-\mathbf{P h}_{2} \mathbf{C}_{\mathbf{n}}$ (dotted line). The results of electrical

measurement are inserted in the figure. These analogous junctions show indistinguishable slopes and intercepts (at the $y$ axis).
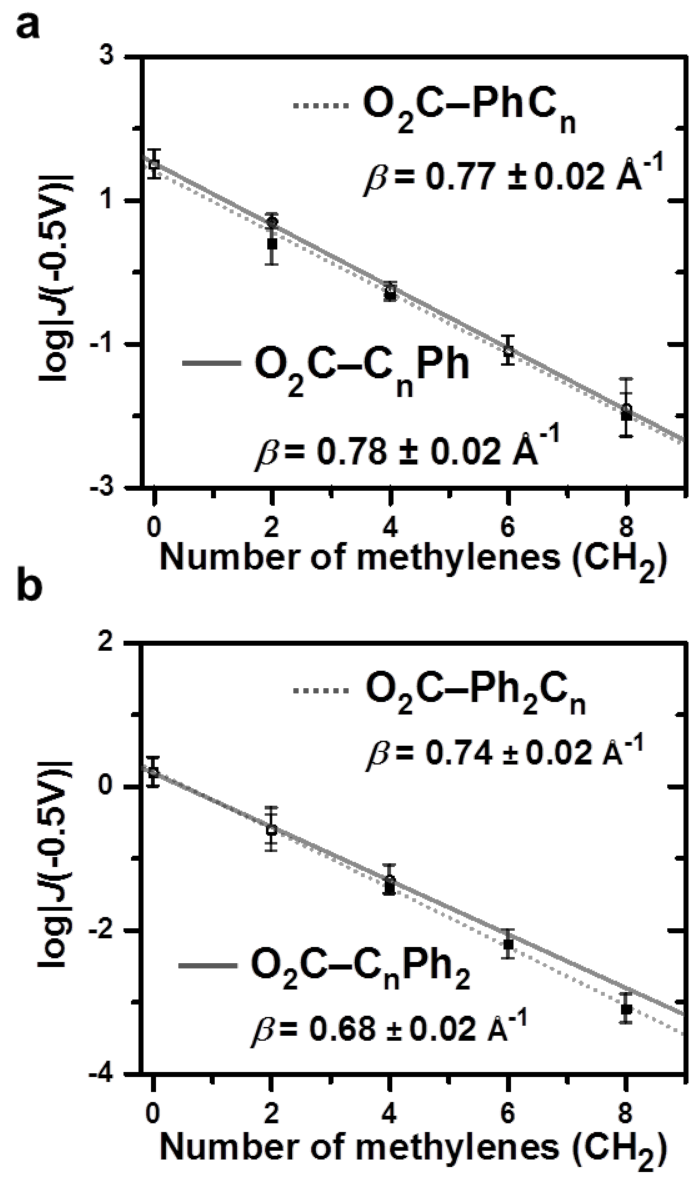
Figure 4. Histograms of $\log |J|$ data derived from (a) $\mathbf{O}_{2} \mathbf{C}-\mathbf{C}_{4} \mathbf{P h}$, (b) $\mathbf{O}_{2} \mathbf{C}-\mathbf{C}_{2} \mathbf{P h C}$, and (c) $\mathbf{O}_{2} \mathbf{C}$ $\mathbf{P h C}_{4}$ at $-0.5 \mathrm{~V}$. Each histogram is fitted with a Gaussian curve (black curve) and the gray dish line aligns $J(-0.5 \mathrm{~V})$ at $1.0 \mathrm{~A} / \mathrm{cm}^{2}$. The current densities for these three isomers are indistinguishable. The value for $\mathbf{O}_{2} \mathbf{C}-\mathbf{C}_{4} \mathbf{P h}$ was adapted from ref. 56.

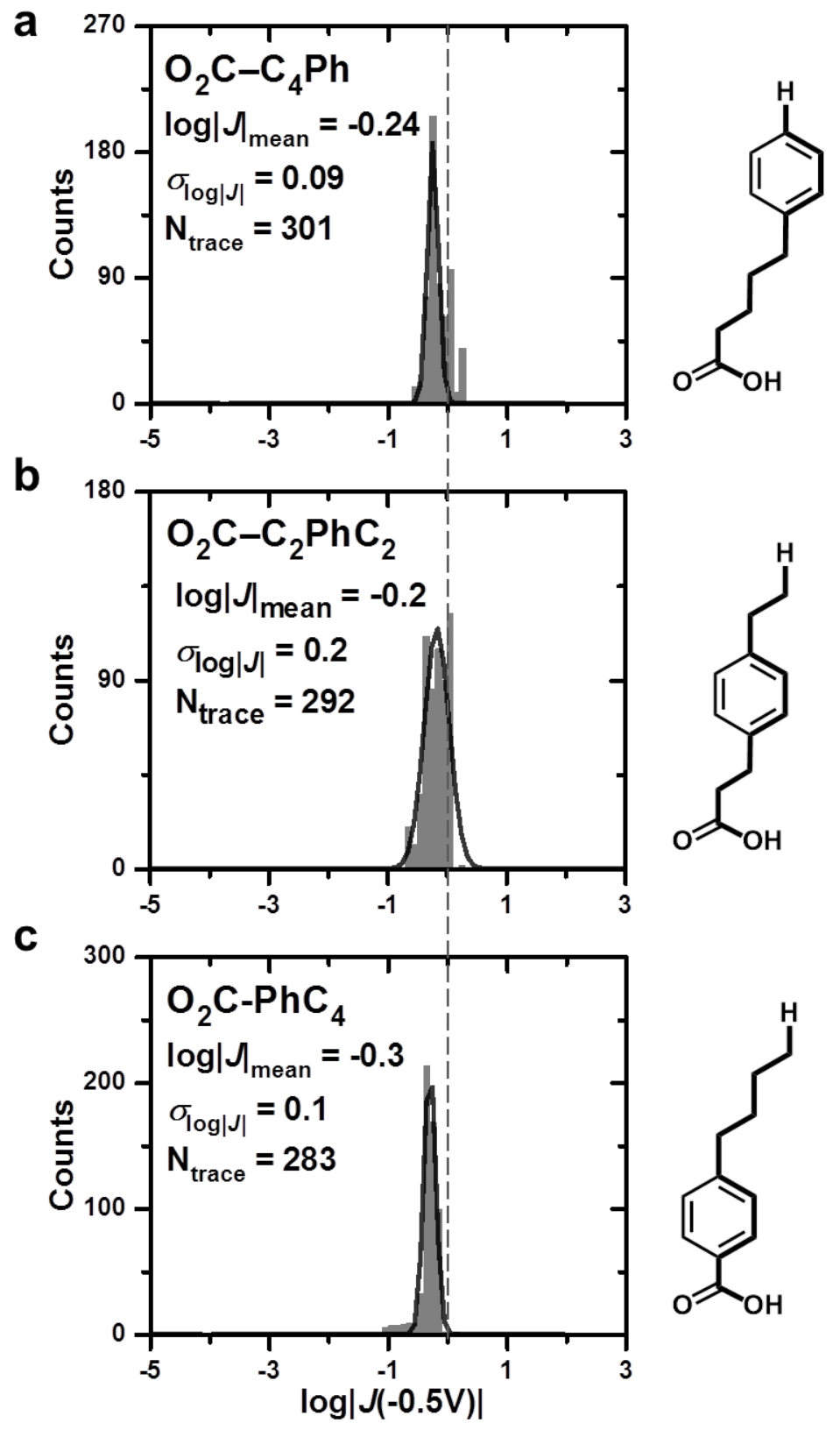


Figure 5. Histograms of $\log |J|$ data derived from (a) $\mathbf{O}_{2} \mathbf{C}-\mathbf{P h C H} \mathbf{C H}_{2}-\mathbf{C H}_{2} \mathbf{P h H}$, (b)

$\mathbf{O}_{2} \mathbf{C}-\mathbf{P h C H}=\mathbf{C H P h H}$, and (c) $\mathbf{O}_{2} \mathbf{C}-\mathbf{P h C} \equiv \mathbf{C P h H}$ at $-0.5 \mathrm{~V}$. Each histogram is fitted with a Gaussian curve (black curve) and the gray dish line aligns $J(-0.5 \mathrm{~V})$ at $1.0 \mathrm{~A} / \mathrm{cm}^{2}$.

a

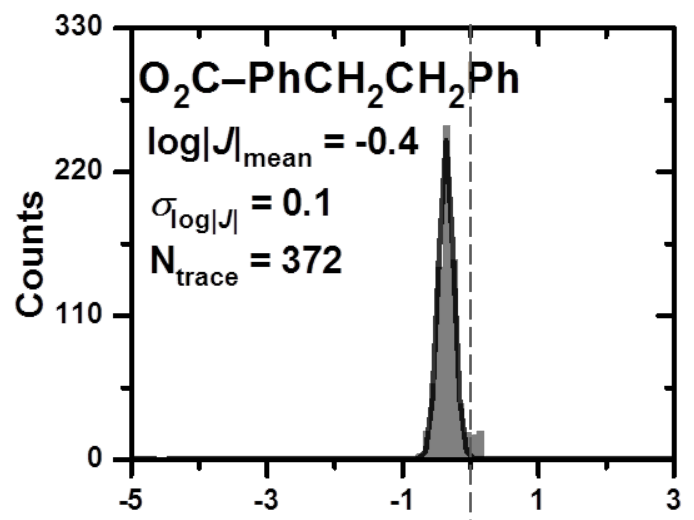<smiles>O=C(O)c1ccc(CCc2ccccc2)cc1</smiles>

b

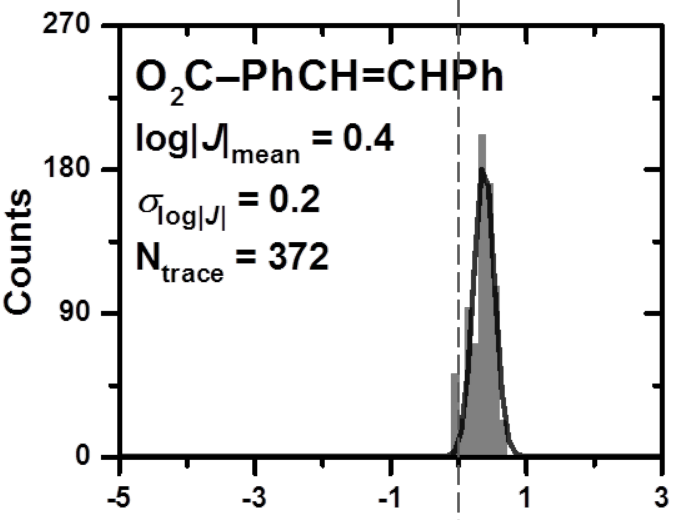<smiles>O=C(O)c1ccc(/C=C/c2ccccc2)cc1</smiles>

C

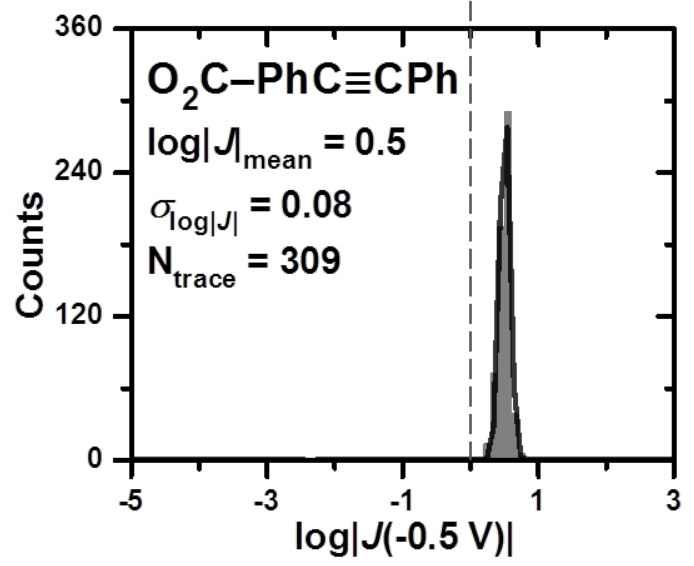<smiles>Cc1ccc(C#Cc2ccc(C(=O)O)cc2)cc1</smiles> 
Table 1. Summary of current densities $\left(\mathrm{A} / \mathrm{cm}^{2}\right)$ derived from junctions comprising SAMs of $\mathbf{O}_{2} \mathbf{C}-\mathbf{C}_{\mathbf{n}} \mathbf{P h} \mathbf{h}_{\mathbf{m}}$ and $\mathbf{O}_{\mathbf{2}} \mathbf{C}-\mathbf{P h} \mathbf{h}_{\mathbf{m}} \mathbf{C}_{\mathbf{n}}$ (where $\mathrm{m}=1,2$ and for $\left.\mathbf{C}_{\mathbf{n}}=\left(\mathrm{CH}_{2}\right)_{\mathrm{n}}, \mathrm{n}=2,4,6,8\right)$ on templatestripped silver substrates at $-0.5 \mathrm{~V}$.

\begin{tabular}{|c|c|c|c|c|}
\hline & $\mathrm{O}_{2} \mathrm{C}-\mathrm{C}_{\mathrm{n}} \mathrm{Ph}$ & $\mathrm{O}_{2} \mathrm{C}-\mathrm{PhC}_{\mathrm{n}}$ & $\mathrm{O}_{2} \mathrm{C}-\mathrm{C}_{\mathrm{n}} \mathrm{Ph} \mathrm{h}_{2}$ & $\mathrm{O}_{2} \mathrm{C}-\mathrm{Ph}_{2} \mathrm{C}_{\mathrm{n}}$ \\
\hline $\mathrm{n}$ & $\log |J| \pm \sigma_{\log }^{a}$ & $\log |J| \pm \sigma_{\log }^{a}$ & $\log |J| \pm \sigma_{\log }^{a}$ & $\log |J| \pm \sigma_{\log }^{a}$ \\
\hline 2 & $0.70 \pm 0.10^{b}$ & $0.4 \pm 0.3$ & $-0.6 \pm 0.3$ & $-0.6 \pm 0.3$ \\
\hline 4 & $-0.24 \pm 0.09^{b}$ & $-0.3 \pm 0.1$ & $-1.3 \pm 0.2$ & $-1.4 \pm 0.1$ \\
\hline 6 & $-1.10 \pm 0.20$ & $-1.1 \pm 0.2$ & N/A & $-2.2 \pm 0.2$ \\
\hline 8 & $-1.90 \pm 0.40$ & $-2.0 \pm 0.3$ & N/A & $-3.1 \pm 0.2$ \\
\hline \multirow[t]{2}{*}{0} & $\log \left|J_{0}\right|=1.6 \pm 0.2$ & $\log \left|J_{0}\right|=1.4 \pm 0.2$ & $\log \left|J_{0}\right|=0.2 \pm 0.2$ & $\log \left|J_{0}\right|=0.2 \pm 0.2$ \\
\hline & $\beta=0.78 \pm 0.02 \AA^{-1}$ & $\beta=0.77 \pm 0.02 \AA^{-1}$ & $\beta=0.68 \pm 0.02 \AA^{-1}$ & $\beta=0.74 \pm 0.02 \AA^{-1}$ \\
\hline \multicolumn{5}{|c|}{$\begin{array}{l}{ }^{a} \text { A linear-least square fit for each series of SAMs yielded a slope and an intercept; the slope is the attenuation } \\
\text { factor, } \beta \text {, for the polymethylene chain and the intercept at the } y \text { axis represents the extrapolated value of the } \\
\text { log-injection current }\left(\log \left|J_{0}\right|\right) \text { when } \mathrm{n}=0 \text {. We estimated the width of the barrier, } d \text { in the Simmons equation, } \\
\text { by the length of the methylene chain }\left(\mathbf{C}_{\mathbf{n}}\right) \text { in } \AA \text { modeled using ChemBio3D software (CambridgeSoft). } \\
{ }^{b} \text { The value was adapted from ref. } 56 \text {. }\end{array}$} \\
\hline
\end{tabular}




\section{TOC}
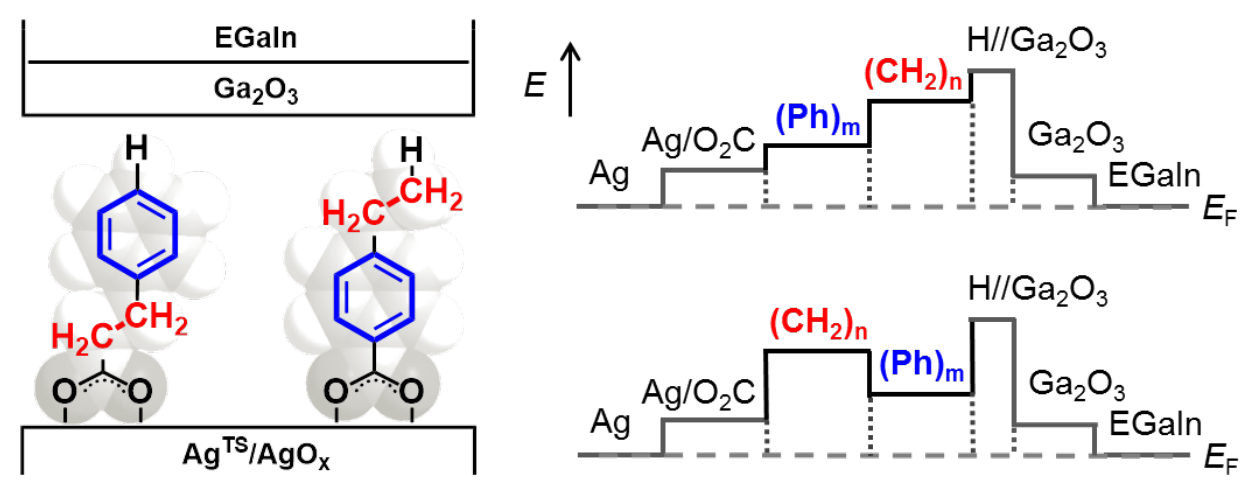